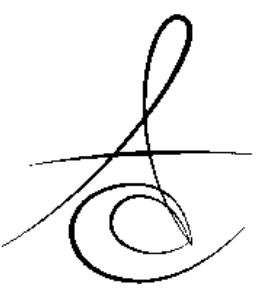

\title{
DİŞ HEKİMLİĞİNDE KULLANILAN BAĞLANMA DAYANIMI TEST METOTLARI
}

\author{
BONDING STRENGTH TEST METHODS IN DENTISTRY
}

Dt. M. Saygın ELMAS*

Doç. Dr. Emine GÖNCÜ BAŞARAN*

Dr. Öğr. Üyesi Ayça Deniz İzGí*

Makale Kodu/Article code: 4274

Makale Gönderilme tarihi: 15.01 .2020

Kabul Tarihi: 04.11.2020

DOI : $10.17567 /$ ataunidfd 820990
M. Saygın Elmas: ORCID ID: 0000-0003-0588-7926

Emine Göncü Başaran: ORCID ID: 0000-0002-5183-7746

Ayça Deniz İzgi: ORCID ID: 0000-0003-2975-4511

\section{öz}

Günümüz diş hekimliğinde, materyallerin yapışma kuvvetlerinin miktarını ölçmek için çeşitli metotlar geliştirilmiştir. Bağlanma dayanımı testleri bu amaç için yaygın olarak kullanılmaktadır. Bununla birlikte birçok bağlanma dayanımı test metodu vardır. Bu yöntemlerin her birinin avantajları ve dezavantajları vardır. Mikro çekme ve mikro makaslama testleri daha hassas sonuçlar verebilir, ancak daha karmaşık test kurulumlarına ihtiyaç duydukları için bazı dezavantajlar meydana gelmektedir ve bu test yöntemlerinde standardizasyonun sağlanması zordur. Bu nedenle bağlanma dayanım testlerinin kendi aralarında kıyaslanması zordur. Bağlanma dayanımı test metotları kullanılırken, testi yapan kişinin test cihazlarının standardizasyonunu bilmesi ve standardizasyon sorunlarının çözümünü yapabilmesi gerekmektedir.

Anahtar kelimeler: Bağlanma dayanımı, bağlanma dayanımı test metotları, diş hekimliği

\section{ABSTRACT}

In today's dentistry, various methods have been developed to measure the amount of adhesive strength of materials. Bonding strength test methods can be used for this commonly. There are many bonding strength test methods for evaluation. Each one of these methods have their advantages and disadvantages. Micro tensile and micro shear test can be more accurate but they have their disadvantage as they need more complicated testing setups and these testing methods have their weakness such as these tests hard to standardize. For this reason, it is diffucult to compare to bonding force between themselves. When bonding strength test methods going to be used, tester should know and take care that standardization issue.

Key Words: Bonding strength, bonding strength test methods, dentistry

* Dicle Üniversitesi Diş Hekimliği Fakültesi Protetik Diş Tedavisi Anabilim Dall, Diyarbakır

Kaynakça Bilgisi: Elmas S, Göncü Başaran E, İzgi D. Diş hekimliğinde kullanılan bağlanma dayanımı test metotları. Atatürk Üniv Diş Hek Fak Derg 2021; 31: 283-8.

Citation Information: Elmas S, Goncu Basaran E, İzgi D. Bonding strength test methods in dentistry. J Dent Fac Atatürk Uni 2021; 31: 283-8.

\section{GİRİş}

İn vivo testler diş hekimliğinde kullanılan materyallerin değerlendirilmesinde önemli yere sahiptir. Ancak bu yapılan testler, ağız içerisinde oluşan farklı streslerin restorasyona yaptıkları etkileri doğru olarak değerlendiremeyebilir. Güncel bağlayıcı ajanların hızlı gelişimi ve ideal ürün arayışı nedeniyle in vitro bağlanma dayanımı testlerine ihtiyaç duyulmaktadır.

Ara yüzey bağlanma dayanımı kuvveti çeşitli yöntemlerle test edilebilir. Yapıştırılan alanın boyutları kullanılarak, bağlanma dayanımı yöntemleri makro (4$28 \mathrm{~mm}^{2}$ ) veya mikro (yaklaşık $1 \mathrm{~mm}^{2}$ ) olarak sınıflan- dırılabilir. ${ }^{1}$ Ara yüze çekme veya makaslama kuvvetleri uygulanabilir. $^{2}$

Bu testler; 3

- Makro Makaslama (shear)

- Makro Çekme (tensile)

- Push-out

- Mikro Makaslama (micro shear)

- Mikro Çekme (micro tensile)'dir.

$\mathrm{Bu}$ testler evrensel test makinası düzeneklerinde yapılırlar. Çeşitli markalar bulunmasına rağmen 
en çok kullanılanlardan biri İnstron (Norwood, Massachusetts, ABD) markasının test cihazıdır.

\section{Makro Makaslama bağlanma dayanımı testi}

Makro makaslama bağlanma dayanımı testinde bağlanmanın gerçekleşeceği parça uygun şartlarda hazırlandıktan sonra evrensel test makinasına yerleştirilir. Makinanın kuvvet uygulayıcı koluna tek açılı çivi şeklinde uç, düz yüzeyli keski ya da tel halka kullanılarak bağlanma dayanımı test edilecek parçaya kuvvet uygulanır. 4,5

Makaslama bağlanma dayanımı test metodunda bıçak sırtı biçiminde yapılan bir aparat yardımı ile diş yüzeyiyle olan bağlantının ayrılabileceği şekilde test uygulanır. ${ }^{4,5}$ ISO standardında test düzeneğinin kesici ucunun çalışma hızının 0,45 ile 1,05 mm/dk arasında olması gerektiği bildirilmiştir.6,7

İki materyalin birbirine bir bağlanma ajanıyla bağlandığı yüzeyde kopma meydana gelene kadar değişmeyen hızla kuvvet uygulanması ilkesine dayanan bu testte, bağlanma dayanımı test sonucunun değeri, elde edilen maksimum kuvvetin bağlanmanın meydana geldiği yüzey alanına bölünmesiyle ölçülür. Bağlanma kuvvetinin değeri, pound/inch ${ }^{2}, \mathrm{~kg} / \mathrm{cm}^{2}, \mathrm{MN} / \mathrm{m}^{2}$ veya $\mathrm{N} / \mathrm{mm}^{2}$ (Mega paskal, MPa) olarak belirtilir. ${ }^{8,9}$

Makaslama bağlanma dayanımı testlerindeki iki materyalin arasındaki bağlanmanın başarısız olması iki materyalin arasındaki bağlantının bozulmasıdır ve bu durumun asıl nedeni gerilme kuvvetidir. Test yapılan yüzeyin kuvvet uygulayıcı kola olan uzaklığı arttıkça uygulanan kuvvetin momenti artacağından uygulanan gerilme kuvveti de artacaktır. ${ }^{10}$

Kuvvet uygulayıcı kolun uzaklığı ve ayarları stres dağılımını etkileyeceğinden bağlanma dayanımı değerleri de değişecektir. Bilgisayarlı FEM (Sonlu Elemanlar Analizi) analizi testinde bulunan sonuca göre çivi uçlu kuvvet kolunun uygulayabileceği maksimum gerilme kuvveti $178 \mathrm{MPa}$, ortalama gerilme kuvveti ise $15 \mathrm{MPa}$ olurken, tel halkayla uygulanan kuvvetin maksimum gerilme kuvveti değeri $69 \mathrm{MPa}$ olmaktadır. ${ }^{11,12}$

Deney örneğinin belirli bir bölgesine kuvvet yoğunlaştırıldığında bağlanma dayanımı kuvveti azalmaktadır. Bu sebepten düz uçlu bir keski ile uygulanan kuvvet, tel halkaya göre daha düşük bağlanma dayanımı kuvveti sonucu vermektedir. Dentinin bağlanma dayanımı değeri 10-50 MPa arasında değerlendirilmektedir. Bağlantı başarısızlıkları genellikle bu değerler arasında bulunmaktadır. ${ }^{13,14}$

Ayrıca makaslama bağlanım testinde kullanılan örnek ile kompozit silindir arasındaki elastik modül farklılığı da bağlanma dayanımı test sonucunu etkiler.
Tipik olarak dentindeki bağlanma dayanımı yaklaşık 10 MPa olarak bulunmuştur. ${ }^{13,14}$

\section{Makro çekme bağlanma dayanımı testi}

Çekme testlerinde kuvvet dağılımı makaslama testlerine göre daha homojen olmaktadır. Bu da bağlanma testi sonuçları için çok daha kararlı sonuçlara yol açmaktadır. Makro çekme bağlanma dayanımı testlerinde, bağlanmış ara yüzün yükleme eksenine dik olarak hizalanması çok önemlidir. Ayarlanmazsa kuvvet örneklerde bükülmeye neden olur. Ayrıca test cihazı, diş yüzeyi ve adeziv materyal arasındaki doğru konumu korumalıdır. Bu nedenlerle çekme testleri makaslama testlerine göre daha fazla teknik hassasiyet gerektirir. ${ }^{15,16}$

\section{Push-out testi}

Bağlanma kuvvetini ölçmek için kullanılan testlerden biridir. Yuvarlak dilim şeklinde hazırlanan dentinin üstüne çalışılacak materyal için uygun boyutta delik açılarak bu deliğe adeziv sistem ile birlikte materyal yerleştirilir ve materyalin çapıyla oranı 0.85 'den az olan sivri bir uçla materyale kuvvet uygulanır. ${ }^{17}$ Ayrılmanın meydana geldiği kuvvet ölçülür. Bu metot klinik ortamı makaslama ve çekme testine göre daha iyi taklit eder çünkü bu metotta test edilen materyalin adeziv sistemle dentine bağlanması sağlanır. ${ }^{18,19}$

\section{Mikro çekme bağlanma kuvvet testi}

Mikro çekme testi için çeşitli test düzenekleri mevcuttur. Örnek, siyanoakrilat yapıştırıcı kullanılarak yapıştırılabilir veya aktif veya pasif olarak test düzeneğine kulplu olarak tutturulabilir. Kavrama yöntemi, numunedeki stres dağılımını engeller. Dentin bağlanma gücü değerleri 30 ila $50 \mathrm{MPa}$ arasında değişmektedir. Mikro çekme bağlanma kuvvet testi yönteminin MPa cinsinden değeri makro çekme testlerinde bulunanlardan daha yüksektir çünkü çatlakların kritik boyutu mikro ara yüzde daha küçük olur. 20,21

Bununla beraber, doku ve örnekler arasındaki bağlantı kuvvetini değerlendirirken dikkat edilmesi gereken bir diğer husus da şöyledir; örnekler elmas frez ile kesilirken meydana gelebilecek mikro çatlaklar, kuvvetin uygulandığı alanda yoğunlaşarak daha düşük bir bağlanma dayanımı kuvveti sonucun çıkmasına neden olabilmektedir. ${ }^{22,23}$

Mikro makaslama bağlanma kuvvet testi

Mikro makaslama testi 2002 yılında araştırmacılara tanıtılmıştır.24,25 Mikro makaslama bağlanma dayanımı test metodu bir tel yardımıyla veya farklı bir düzenek ile diş dokusunun ya da bir materyalin üzerine yerleştirilen örneklerin bağlanma dayanımlarının ölçüldüğü bir test metodudur. Bağlanma dayanımı 
ölçülen materyallerin yüzey alanı $1 \mathrm{~mm}^{2}$ 'den daha küçüktür. Mikro makaslama bağlanma kuvvet testlerinden biri örnek verilecek olunursa; deney yapılacak materyal $0.5 \mathrm{~mm}$ çapında, $0.7 \mathrm{~mm}$ yüksekliğinde silikon tüpler kullanılarak kompozit silindirin üzerine konumlandırıır. Genellikle, 6 parça tüp yüzeye bağlanarak kompozit ile doldurulur. Test prosedürleri makro makaslama testi ile benzerlik gösterir. Stres dağılımındaki negatif özellikler de aynı şekilde benzerlik gösterir.26,27

Avantajları arasında;28,29

- Tek bir diş için ortalama değerin hesaplanabilmesi,

- Bir dişten birden fazla test örneği elde edilebilmesi,

- Düzensiz yüzey varlığında testin yapılabilmesinin mümkün olması,

- Örneklerin deneylerden sonra elektron mikroskopunda daha kolay incelenebilmesi sayılabilir.

Bağlanma Dayanımı Testi Esnasında Oluşan Başarısızlık Tipleri

Bağlanma dayanımının test edildiği örneklerde meydana gelen kopma tipleri, adeziv bir bağlanma gösteren materyallerin ağırlık dirençleriyle etkilenir. Test sonrasında oluşan kırık tipleri belirlenirken, kopma yüzeyleri görsel olarak ya da SEM (Taramalı Elektron Mikroskobu) mikroskobu kullanılarak incelenebilir. Kopma tipleri, meydana gelme şekillerine göre; adeziv, koheziv veya karışık (mixed) başarısızlık olarak değerlendirilir.7,9

Adeziv başarısızlıklar, farklı materyaller arasında oluşan başarısızıklardır. Koheziv başarısızlıklar, bir materyalin kendi bünyesine meydana gelen başarısızıklardır. Hem koheziv, hem de adeziv başarısızlıkların eş zamanlı meydana gelebildiği başarısızlıklar ise karışık başarısızlıklardır. ${ }^{30,31}$

Zayıf bağlantılı ajan kullanılan sistemlerde görülen başarısızlık tipi genellikle adeziv başarısızlık tipidir. Rezin materyal ile dentin yüzeyi arasında ya da rezin materyal ile bağlanan sistem arasında ayrılma meydana gelir. Böyle durumlarda yalnızca minimal rezin penetrasyonu meydana gelir. Güçlü bağlayıcı ajan kullanılan sistemlerde daha çok görülen koheziv başarısızlık ise bağlayıcı rezin siman sisteminin kendi içerisinde meydana gelen başarısızlık tipidir. ${ }^{32,33}$

al-Salehi ve arkadaşları ${ }^{34}$ bağlanma kuvveti ile başarısızık tipleri arasında ilişkiyi rapor etmiş ve bağlanma değeri yükseldikçe dentin kırıklarının ve karışık başarısızlığın daha fazla gözlendiğini belirtmişlerdir. Güncel bağlayıcı sistemlerle gerçekleştirilen makaslama bağlanma dayanımı testlerinde, bağlanılan yüzey ile materyal arasında bağlanma dayanımı kuvveti değerlendirildiğinde daha çok koheziv başarısızıklar görülmekte, bu başarısızlıklar da bağlayıcı sistemlerin klinik başarısını belirlemektedir. ${ }^{35,36}$ ları; $37,38.39$

Mikro bağlanma dayanım testlerinin avantaj-

- Daha büyük değerlerde ara yüz-bağlanma dayanımı kuvveti ölçülebilmesi,

- Değişkenlerin ve ortalama değerlerin bir diş için hesaplanabilmesi,

- Pürüzlü yüzeylerde test yapılabilmesi,

- Daha küçük yüzeylerde test yapılabilmesi.

Mikro bağlanma dayanım testlerinin dezavantajlarl; 37,38,39

- Teknik hassasiyetin fazla olması,

- Çok düşük bağlanma kuvvetlerinin test edilebilmesinin zorluğu,

- Kullanılacak olan dişlerin dehidrate olabilmesi,

- Kullanılacak dişlerin kolaylıkla zarar görebilmesi,

- Kullanılan örneklerin test cihazından ayrılırken zarar görebilmesi,

- Yapılacak test için hazırlanmış özel bir düzenek yapılması, düzenek yapılmadan yapılan testlerde istenen geometrik şeklin ve yüzey cilasının yapılamaması,

- Örneklerde oluşan kırıkların nerede oluşabileceğinin ön görülememesi,

- Testin uygulanmasıyla ilgili standardın olmaması olarak sayılabilir.

Bağlanma dayanımı test metotları ile ilgili birçok araştırma yapılmış ve çeşitli sonuçlar ortaya konulmuştur. Mikro ve makro çekme bağlanma dayanımı test metotları karşılaştırıldığında, El Zohairy ve arkadaşları ${ }^{40}$ 2010 yılında yapmış oldukları araştırmalarında mikro çekme testinin daha başarılı sonuç verdiğini göstermişlerdir.

Mikro bağlanma dayanımı testlerinin teknik hassasiyet gerektirdiğini, Sirisha ve arkadaşlarının ${ }^{12}$ 2014 yılında yapmış oldukları çalışmayı örnek vererek açıklamak mümkündür. Yapılan çalışmada, geleneksel bağlanma dayanımı testleri (makaslama, mikro-makaslama, çekme, mikro-çekme) kullanılarak bağlanama dayanımı kuvveti hesaplanacaksa, bağlanma dayanımı hesaplaması için sadece adeziv başarısızlıklar veya \%10'dan küçük rezin veya dentin tutulumu olan karışık başarısızlıklar dikkate alınması gerektiğini bildirmişlerdir. Bu gözlem de ancak stero mikroskop ya da SEM (Taramalı Elektron Mikroskopu) mikroskobu kullanılarak yapılabilir.

Bağlanma dayanımı testleri diş hekimliği literatüründe bolca kullanılır. ${ }^{10}$ Bununla birlikte klinik 
kullanım alanındaki bazı kısıtlamalar nedeniyle seçim test kriterleri değişmektedir. Bu kısıtlamalara kısaca değinecek olursak bunlar:

Ara yüzdeki gerilmeler düzgün dağılmaz. ${ }^{17}$ Bağlanma kuvvetinin değeri (MPa cinsinden) hesaplanırken, bağlanma dayanımının başarısız olduğu değerin (Newton cinsinden) tüm bağlanmış alanın boyutuna ( $\mathrm{mm}$ kare cinsinden) bölünmesiyle rapor edilir. ${ }^{7,8} \mathrm{Bu}$ genellikle doğru değildir, çünkü ara yüzdeki stres dağıIımı homojen değildir. Bağlanmanın bozulması genellikle büyük kusurlu alanın çevresinde stres birikmesiyle meydana gelir. ${ }^{41}$ Çatlak ilerlemesini başlatan gerçek gerilme seviyesi, ortalama değerden birkaç kat daha yüksek olabilir. ${ }^{42}$ Bu nedenle, ortalama bağlanma kuvveti, bağlanmanın başarısız olduğu değeri tam anlamıyla temsil edemez.

Çatlak çekme kuvveti gerilimi sırasında uygulanan kuvvetin yoğunluğuna bağlı olarak dentin ve mine içerisinde yayılabilir. Bu da kuvvet değerlendirmesinin hatalı yapılmasına neden olabilir. ${ }^{43,44}$

Bağlanma dayanımı kuvvetinin değerlendirildiği çeşitli çalışmaların sonuçları karşılaştırılabilir değildir. Bağlanma dayanımı kuvveti sonuçları kullanılan yüzeylere göre değişik sonuçlar vermektedir. Bunun nedenleri arasında yapışacak yüzeyler arasındaki hazırlık farklııkları, örneklerin değişken olması, yapıştırıcı ajanIarın saklama koşulları sayılabilir. Ayrıca araştırma laboratuvarları arasındaki standartlar da farklılık göstermektedir. ${ }^{12}$

Bağlanma dayanımı testleri kesin sonucu belirlemede yeterli değildir. Yukarıdaki açıklamalara dayanarak, iyi bir klinik performansla ilişkilendirilebilecek bir eşik bağlanma dayanımı kuvveti değeri belirlenemez. Bununla birlikte, bazı adeziv sistemler için literatürde benzer yaklaşımlar bulunabilir. İn vitro düşük performans gösteren sistemler genellikle düşük klinik performansa sahiptir.

Bağlanma dayanımı test değerlerini etkileyebilecek çok sayıda değişkenin varlığından dolayı çeşitli üreticiler ve araştırmacıların aynı ürünler ile ilgili gösterdiği test sonuçları farklı olabilir ve karşılaştırımaları pek sağlıklı olmayabilir. ${ }^{45,46} \mathrm{Bu}$ nedenle, Uluslararası Standardizasyon Organizasyonu (ISO), "Dental materials-testing of adhesion to tooth structure" başlıklı makaleyi yayınlayarak, üreticiler ve araştırmacıların belirtilen prosedürlere uymaları neticesinde elde edilecek verilerin, klinik sonuçlarla karşılaştırılabilecek standartlara ulaşmasında yardımcı olabilmesini hedeflemiştir.

\section{SONUÇ}

Makro ve mikro bağlanma dayanımı testleri ile biyomateryallerin diş dokusuna bağlanma dayanımları ölçülebilir ve bu sayede materyallerin ağız ortamındaki davranışları değerlendirilebilir. ${ }^{47}$ Fakat bu testlerde elde edilen sonuçlar birçok faktörden etkilenebilir. ${ }^{48} \mathrm{Bu}$ faktörler nedeniyle yapılan çalışmalar belirli bir standardizasyona sahip olması çok zordur ve bağlanma dayanımı kuvveti değeri için ortalama eşik değerden bahsetmek her zaman mümkün olmaz. Bu ortalama eşik değerinin olmaması, en yüksek bağlanma kuvveti değerine sahip adeziv sistemi belirlemeyi zorlaştırıc bir faktör olarak günümüz araştırmacılarının üzerine çalıştığı bir konu olarak kalmaya devam etmektedir.

Bu çalışma, çalışmayı yürüten tüm yazarlar tarafindan okunmuş ve onaylanmış orijinal bir çalışmadır. Herhangi bir yazar, kurum ya da kuruluş ile çıkar çatışması olmadığını belirtilmek isteriz.

\section{KAYNAKLAR}

1. David H. Pashley, Ricardo M, Carvalho, Hidehiko Sano, Masatosiii Nakajima, Masahiro Yoshiyama, YasuoSinono, Carios A. Fernandes, Franklin Tay. The microtensile bond test: a review. J Addesive Dent 1999; 1:299-309.

2. Choudhary K, Nandlal B. Comparative evaluation of shear bond strength of nano-hydroxyapatite incorporated glass ionomer cement and conventional glass ionomer cement on dense synthetic hydroxyapatite disk: An in vitro study. Indian J Dent Res 2015; 26:170-5.

3. Sirisha K, Rambabu T, Shankar YR, Ravikumar P. Validity of bond strength tests: A critical review: Part I. J Conserv Dent 2014;17:305-11

4. Devatha $A B$, Lakshmi $M N$, Kumar NB, Erukala $S$, Valluri $R$, Ealla KKR. A comparative study of shear bond strength of direct bonding system with and without a liquid primer: an in vitro study. J Pharm Bioallied Sci 2019;11: 515-22.

5. Kansal R, Rani S, Kumar M, Kumar S, Issar G. Comparative evaluation of shear bond strength of newer resin cement (relyx ultimate and relyx u200) to lithium disilicate and zirconia ceramics as Influenced by thermocycling. Contemp Clin Dent 2018;9:601-6.

6. Technical specification ISO/TS 11405. Dental materials -testing of adhesion to tooth structure. Switzerland; 2003. 
7. Inokoshi M, De Munck J, Minakuchi S, Van Meerbeek B. Meta-analysis of bonding effectiveness to zirconia ceramics. J Dent Res 2014; 93: 329-34.

8. Greig V. Craigs. Restorative dental materials. $\mathrm{Br}$ Dent J 2012; 213: 96-8.

9. Salz $U$, Bock $T$. Testing adhesion of direct restoratives to dental hard tissue - a review. J Adhes Dent 2010;12:343-71

10. Braga RR, Meira JB, Boaro LC, Xavier TA: Adhesion to tooth structure: $A$ critical review of "macro" test methods. Dent Mater 2010; 26:3849.

11. Van Meerbeek B, Peumans M, Poitevin A, et al: Relationship between bond-strength tests and clinical outcomes, Dent Mater 2010; 26:100-21.

12. Sirisha K, Rambabu T, Ravishankar Y, Ravikumar P. Validity of bond strength tests: A critical reviewPart II. J Conserv Dent 2014;17:420-6

13. Drummond JL, Toepke TR, King TJ. Thermal and cyclic loading of endodontic posts. Eur J Oral Sci 1999;107:220-4.

14. Otani A, Amaral M, May LG, Cesar PF, Valandro LF. A critical evaluation of bond strength tests for the assessment of bonding to Y-TZP. Dent Mater 2015; 31: 648-56.

15. Van Noort R, Noroozi S, Howard IC, Cardew G. A critique of bond strength measurements. J Dent 1989; 17:61-7.

16. Kelly JR, Benetti $P$, Rungruanganunt $P$, Bona AD. The slippery slope: critical perspectives on in vitro research methodologies. Dent Mater 2012;28:4151.

17. Chen WP, Chen YY, Huang SH, Lin CP. Limitations of push-out test in bond strength measurement. J Endod 2013; 39: 283-7.

18. Ungor M, Onay EO, Orucoglu H. Push-out bond strengths: The Epiphany-Resilon endodontic obturation system compared with different pairings of Epiphany, Resilon, $\mathrm{AH}$ Plus and gutta-percha. Int Endod J 2006; 39: 643-7

19. Guan G, Takano-Yamamoto T, Miyamoto M, Hattori T, Ishikawa K, Suzuki K. Shear bond strengths of orthodontic plastic brackets. Am J Orthod Dentofacial Orthop 2000;117:438-43.

20. Samsfi S, Van Noort R, Do dentin bond strength tests sefve a useful purpose? J Adhes Dent 1999; $1 ; 57-67$.

21. Thammajaruk $P$, Buranadham $S$, Thanatvarakorn O, Ferrari M, Guazzato M. Influence of glass- ceramic coating on composite zirconia bonding and its characterization. Dent Mater 2019;35:105-13.

22. Versiuis A, Tantbirojn D, Dougias WiH. Why do shear bond tests pull out dentin? J Dent Res 1997; 76:1298-307.

23. Wang R, Shi Y, Li T, Pan Y, Cui Y, Xia W. Adhesive interfacial characteristics and the related bonding performance of four self-etching adhesives with different functional monomers applied to dentin. J Dent 2017;62:72-80

24.Shimada $Y$,Senawongse $P$, Harnirattisai $C$, Burrow MF, Nakaoki Y, Tagami J. Bond strength of two adhesive systems to primary and permanent enamel. J Op Dent 2002;27:403-9

25. Pamato $S$, do Valle $A L$, de Andrade GH, Vidotti $H A$, Só MV, Pereira JR. Does hybridized dentin affect bond strength of self-adhesive resin cement? J Clin Exp Dent 20161;8:409-14.

26. Sadr A, Ghasemi A, Shimada Y, Tagami J. Effects of storage time and temperature on the properties of two self-etching systems. J Dent 2007;35:21825.

27. Flury S, Peutzfeldt A, Lussi A. Two pre-treatments for bonding to non-carious cervical root dentin. Am J Dent 2015;28:362-6.

28. Armstrong S, Geraldeli S, Maia R, Raposo LH, Soares $\mathrm{CJ}$, Yamagawa J. Adhesion to tooth structure: a critical review of "micro" bond strength test methods. Dent Mater 2010; 26: 5062.

29. Ezoji F, Tabari K, Jaberi Ansari Z, Torabzadeh $\mathrm{H}$, Kharrazi Fard $\mathrm{MJ}$. Shear bond strength of a resin cement to different alloys subjected to various surface treatments. J Dent (Tehran). 2016; 13:2939.

30. Price RBT, Gordon C. Hall. In vitro comparison of 10-minute versus 24-hour shear bond strengths of six dentin bonding systems. Quintessence Int 1999; 30: 122-34.

31. Meiers JC, Kazemi RB, Donadio M. The influence of fiber reinforcement of composites on shear bond strengths to enamel. J Prosthet Dent 2003; 89: 388-93.

32. Triolo PT, Swift EJ. Shear bond strengths of ten dentin adhesive systems. Dent Mater 1992; 8: 370-4.

33. Andrade de Freitas SL, Brandt WC, Miranda ME, Vitti RP. Effect of thermocycling, teeth, and polymerization methods on bond strength teethdenture base. Int J Dent 2018; 4: 237-327. 
34. al-Salehi SK, Burke FJ. Methods used in dentin bonding tests: an analysis of 50 investigations on bond strength. Quintessence Int. 1997;28:717-23.

35. Peterson J, Rizk M, Hoch M, Wiegand A. Bonding performance of self-adhesive flowable composites to enamel, dentin and a nano-hybrid composite. Odontology 2018;106: 171-80.

36. Mason PM, Ferrari M, Cagidiaco MC, Davidson CL, Shear bond strength of four dentinal adhesives applied in vivo and in vitro. J Dent 1996; 24: 21722.

37. Lyann SK, Takagaki T, Nikaido T, Uo M, Ikeda M, Sadr A, Tagami J. Effect of different surface treatments on the tensile bond strength to lithium disilicate glass ceramics. J Adhes Dent 2018; 20:261-8.

38. Paul SJ, Welter DA, Ghazi M, Pashley D. Nanoleakage at the Dentin Adhesive Interface vs ĩTensile Bond Strength. Oper Dent 1999; 24: 1818.

39. Rosa WL, Piva E, Silva AF. Bond strength of universal adhesives: A systematic review and meta-analysis. J Dent 2015; 43: 765-76.

40.El Zohairy AA, Saber MH, Abdalla AI, Feilzer AJ. Efficacy of microtensile versus microshear bond testing for evaluation of bond strength of dental adhesive systems to enamel. Dent Mater 2010; 26: 848-54.

41. Mallick R, Sarangi P, Mohanty S, Behera S, Nanda S, Satapathy SK. Micro-tensile bond strength of different adhesive systems on sound dentin and resin-based composite: An in-vitro study. J Conserv Dent 2015; 18: 379-83.

42. Costa LA, Carneiro KK, Tanaka A, Lima DM, Bauer J. Evaluation of $\mathrm{pH}$, ultimate tensile strength, and micro-shear bond strength of two self-adhesive resin cements. Braz Oral Res 2014; 28:1-7.

43. Ritter AV, Sulaiman TA, Rodgers BM, Baratto-Filho F, Cunha L, Gonzaga CC, Correr GM. Effect of surface treatment and cement type on dentin bonding of processed resin composite. Am J Dent 2019; 32: 271-5.

44. Román-Rodríguez JL, Agustín-Panadero R, AlonsoPérez-Barquero J, Fons-Font A, Solá-Ruíz MF. Shear bond strength of partial coverage restorations to dentin. J Clin Exp Dent 2015; 7: 396-9.
45. Sano $H$, Shono $T$, Sonoda $H$, Pashley DH. Relationship between surface area for adhesion and tensile bond strength-evaluation of a microtensile test. Dent Mater 1994; 10: 236-40

46. Kasraie S, Shokripour M, Safari M. Evaluation of micro-shear bond strength of resin modified glassionomer to composite resins using various bonding systems. J Conserv Dent 2013;16:550-4.

47. Başaran G, Göncü Başaran E, Ayna E, Değer $Y$, Ayna B, Tuncer MC. Microtensile bond strength of root canal dentin treated with adhesive and fiberreinforced post systems. Braz Oral Res 2019; 1: e027.

48. Tekçe N, Demirci M. Mikrogerilim bağlanma dayanım testi ve sonuçlarını etkileyen etkenler. J Dent Fac Atatürk Uni 2015; 24: 134-52.

\section{Sorumlu Yazarın Yazışma Adresi}

Doç. Dr. Emine Göncü Başaran

Dicle Üniversitesi

Diş Hekimliği Fakültesi

Protetik Diş Tedavisi Anabilim Dalı/ Diyarbakır Tel: 05322602000

Email: eminegb@hotmail.com 